\title{
Molecular analysis of lily leaves in response to salicylic acid effective towards protection against Botrytis elliptica
}

\author{
Yu-Yen Lu, Chao-Ying Chen * \\ Department of Plant Pathology and Microbiology, National Taiwan University, No. 1, Sec. 4, Roosevelt Rd., Taipei 106, Taiwan, R.O.C.
}

Received 4 September 2004; received in revised form 27 January 2005; accepted 28 January 2005

Available online 17 March 2005

\begin{abstract}
The phytopathogenic fungus Botrytis elliptica (Berk.) Cooke causes necrosis and blight symptoms in lily leaves. Development of necrotic lesions in the leaves of Oriental lily cultivar Star Gazer could be suppressed by application of salicylic acid (SA) or previous infection by $B$. elliptica. In our observation, accumulation of $\beta$-1,3-glucan polymer in the guard cells and anticlinal walls of epidermis appeared more prominent in SA-treated leaves after B. elliptica infection as compared to that in SA-treated leaves with mock inoculation or in B. ellipticainoculated leaves without SA treatment. Higher ratio of closed stomata appeared in SA-treated leaves after mock or $B$. elliptica inoculation, but less in B. elliptica-infected leaves without SA treatment. In molecular analysis of gene expression in response to SA treatment, a cDNA sequence coding for 138-amino acid protein was identified by suppression subtractive hybridization, followed by differential screening and $5^{\prime}$ RACE cDNA amplification. This putative protein designated LsGRP1 shared homology with several glycine-rich proteins present in plant extracellular matrix. Northern blot analysis detected an increase of LsGRP1-related mRNA transcript in 'Star Gazer' leaves after SA treatment, and also in B. elliptica-infected and upper un-inoculated leaves. When B. elliptica was inoculated on SA-treated leaves, accumulation of LsGRP1-related mRNA transcript appeared earlier as compared to that without SA treatment. That LsGRP1 or its homologues playing a role in SA and pathogen-induced defense responses in lily was thus presumed.
\end{abstract}

(C) 2005 Elsevier Ireland Ltd. All rights reserved.

Keywords: Lily; Salicylic acid; $\beta-1,3-$ Glucan polymer; Stomatal closure; Glycine-rich protein; Botrytis elliptica

\section{Introduction}

Plants have evolved sophisticated preformed and induced defense mechanisms against pathogens and herbivorous insects. Localized infection by pathogens induces resistance to a wide range of pathogens such as fungi, bacteria or viruses, locally and systemically in the un-infected parts of the plant $[1,2]$. The defense mechanisms include various physical, physiological and biochemical alterations involving induction or potentiation of expression of a number of defense-related genes [1,3-6]. Salicylic acid (SA) is an endogenous signal for the activation of plant defense responses and essential for the expression of systemic acquired resistance (SAR) in many plants [7-10]. As known, exogenous application of SA induces plant resistance to

\footnotetext{
* Corresponding author. Tel.: +886 2 23657735; fax: +886 223636490 .

E-mail address: cychen@ntu.edu.tw (C.-Y. Chen).
}

different kinds of pathogens, that is associated with oxidative burst, cell wall enforcement, up- or downregulation of gene expression, etc. [11,12].

Botrytis leaf and blossom blight, incited by Botrytis elliptica (Berk.) Cooke, causes severe losses in the cutflower and bulb productions of lilies (Lilium spp.) in Taiwan [13]. Since this fungal infection occurs within a very short time under suitable conditions $[13,14]$, frequent applications of fungicides are generally required to prevent prevalence of the disease. However, fungicide-resistant strains of $B$. elliptica have evolved frequently [15] and the efficacy of fungicide control of this disease is not always promising. During the last few years, application of plant activators to induce resistance becomes a new strategy for plant disease control $[11,12,16]$ and is expected to be an alternative for effective and sustainable management of Botrytis blight in lilies [17]. Since multiple components are involved in the mechanisms of plant defense, the efficacy of induced 
resistance would last longer than that of protection by fungicide application. Understanding of plant defense responses would stimulate discovery of useful resources from plants and facilitate the development of effective disease control measures.

In this communication, we presented the effect of SA application in the control of Botrytis leaf blight in Oriental lily cultivar Star Gazer to show the potential of induced resistance in the protection of lily plants from fungal attack. The alterations of 'Star Gazer' leaves in response to SA treatment and $B$. elliptica infection were examined microscopically and analyzed molecularly to demonstrate the induced responses in this monocotyledonous plant. Microscopical examination mainly focused on the alterations of leaf epidermis, in particular the presence of $\beta-1,3-$ glucan polymer and the stomatal opening. An attempt to clone defense-related genes induced by SA were conducted by suppression subtractive hybridization [18] and differential screening. By this approach, a SA-induced cDNA was identified from 'Star Gazer' leaves and used to demonstrate the inducibility of gene expression in response to SA and $B$. elliptica.

\section{Materials and methods}

\subsection{Plant material and fungal culture}

The bulbs of Oriental lily cv. Star Gazer were planted in $14 \mathrm{~cm}$ pots (one bulb per pot) containing potting mix of a commercial medium (Bas Van Burren, Maasland, The Netherlands) and perlite at a ratio of 3:1, and grown in a growth room at $20-23{ }^{\circ} \mathrm{C}$ with $12 \mathrm{~h} / 12 \mathrm{~h}$ light/dark cycle for 15-30 days. B. elliptica strain B061-1 was grown on V-8 agar (20\% V-8 vegetable juice (Campbell soup group), $0.3 \%$ $\mathrm{CaCO}_{3}, 1.5 \%$ agar) under near-UV light for 5 days $[19,20]$. The conidia were collected from fungal culture by gently vortexing in Tween 20 solution $(0.05 \%$ Tween 20 in sterile deionized water) and the conidial suspension was adjusted to a concentration of $5 \times 10^{4}$ conidia/ml.

\subsection{SA treatment and pathogen inoculation for observation of induced resistance to B. elliptica}

SA solution was freshly prepared by dissolving sodium salt of salicylic acid (Sigma Chemical Co., St. Louis, MO, USA) in deionized water. SA solution was drenched into the rhizosphere of each lily plant in a concentration of $0.4 \mathrm{mmol} / \mathrm{kg}$ potting mix before fungal inoculation. Conidial suspension of B. elliptica was atomized on the abaxial surface of middle leaves. Four leaves per plant were inoculated. Five plants were used for each treatment. In addition, for observation of SAR phenomenon, conidial suspension of B. elliptica was atomized on the upper leaves different days after first inoculation on the middle leaves of lily plants. Four leaves of each portion were inoculated.
Lesion development was observed and recorded 3 days after inoculation. Normally, lily plants of 30 days old were inoculated with conidial suspension.

\subsection{Histological examination of lily leaves}

Fully expanded leaves in the middle portion of lily plants were detached and placed in Petri dishes for experiments. The cut end of the petioles was immersed in $0.1 \mathrm{mM} \mathrm{SA}$ solution or deionized water for different periods before microscopical examination. To investigate the effect of SA treatment on fungal attack, conidial suspension (6-8 drops per leaf, $10 \mu$ l each drop) was placed on the abaxial surface of lily leaves $24 \mathrm{~h}$ after SA treatment. Tween 20 solution was used for mock inoculation. For microscopical examination, lily leaves were processed through a procedure of aniline blue staining [20,21]. The leaves were immersed in $1 \mathrm{M} \mathrm{KOH}$ solution and autoclaved at $121^{\circ} \mathrm{C}$ for $15 \mathrm{~min}$, followed by three rinses with deionized water to remove $\mathrm{KOH}$ solution. Subsequently, the leaves were flooded with aniline blue dye $(0.05 \%$ aniline blue WS (Mallinckrodt Baker, Inc., Phillipsburg, NJ, USA) in $0.067 \mathrm{M} \mathrm{K}_{2} \mathrm{HPO}_{4}, \mathrm{pH} 9.0$ ) and examined by epifluorescence illumination $(340-380 \mathrm{~nm}$ excitation filter, $400 \mathrm{~nm}$ chromatic bean splitter, $425 \mathrm{~nm}$ barrier filter; Leica DM IL, Wetzlar, Germany). The images were captured with a digital camera (COOLPIX990, Nikon, Japan). Aniline blue has been used to detect amorphous $\beta$-1, 3-glucan polymer constituent of fungi and plants [22,23]. In addition, stomata were examined and the ratios of closed stomata in microscopical fields were recorded. The data were collected from ten fields for each treatment.

\subsection{Subtractive hybridization and PCR amplification}

The rhizosphere of lily plants was drenched with SA solution in a concentration of $0.4 \mathrm{mmol} / \mathrm{kg}$ potting mix. The middle leaves were collected after SA treatment daily for three times and stored at $-80{ }^{\circ} \mathrm{C}$ until pulverized in liquid nitrogen and extracted for RNA as a tester to screen differentially expressed mRNAs. Lily plants applied with equivalent amount of deionized water instead of SA solution were used to extract RNA as a driver. Total RNA was extracted from lily leaves using RNA extraction buffer (200 mM ammonium carbonate, 2\% SDS, $2 \mathrm{mM}$ disodium EDTA, $200 \mu \mathrm{g} / \mathrm{ml}$ bentonite, $1 \%$ 2-mercaptoethanol) followed by purification with acid phenol which was mixed with chloroform and isoamyl alcohol (24:1) at a ratio of 1:1, for at least three times. Two further RNA purification steps were conducted. In the first step, total RNA was precipitated by mixing with equal volume of $5 \mathrm{M}$ lithium chloride overnight and collected by centrifugation at $4{ }^{\circ} \mathrm{C}$ for $20 \mathrm{~min}$; subsequently, the RNA pellet was washed with $2 \mathrm{M}$ lithium chloride and re-dissolved in RNase-free water. In the second step, total RNA was re-precipitated by mixing with 0.1 volume of $3 \mathrm{M}$ sodium acetate $(\mathrm{pH} 4.8)$ and 2.5 volume of 
95\% ethanol. The RNA pellet was washed with 95\% ethanol, air-dried and dissolved in RNase-free water before being stored at $-80{ }^{\circ} \mathrm{C}$. Poly $(\mathrm{A})^{+}$mRNA was purified from total RNA using the Oligotex mRNA Mini Kit (QIAGEN, Hilden, Germany) and quantified spectrophotometrically. Equivalent amounts of poly $(\mathrm{A})^{+}$mRNA from tester and driver RNA were converted to cDNAs. Afterwards, cDNA subtractive hybridization at $68{ }^{\circ} \mathrm{C}$ was performed according to the procedure described by the manufacturer (Clontech Laboratories, Inc., Palo Alto, CA, USA). The subtracted cDNA fragments was amplified by the Advantage 2 PCR enzyme mix (Clontech) and cloned into pGEMTeasy (Promega Corp., Madison, Wisconsin, USA). The resulting plasmids were transformed into Escherichia coli DH5 $\alpha$ (Bethesda Research Laboratories).

\subsection{Differential screening of PCR-select subtracted cDNA clones}

The cDNA inserts in randomly selected clones were amplified by PCR with nested primers 1 and 2R (Clontech) and screened by hybridization to identify SA-induced mRNAs. The PCR products were purified, arrayed on duplicate Hybond ${ }^{\mathrm{TM}}-\mathrm{N}^{+}$nylon membranes (Amersham Biosciences UK Limited) and differentially screened with digoxigenin (DIG)-labeled cDNAs prepared by RT-PCR from the leaf mRNA of SA-treated or the control lily plants. The cDNA clones corresponding to SA-induced mRNAs were selected and the sequence similarities were examined by cross-hybridization.

\subsection{RNA blot analysis}

After the rhizosphere of lily plants was drenched with SA solution in a concentration of $0.4 \mathrm{mmol} / \mathrm{kg}$ potting mix for different periods, the leaves were harvested and stored at $-80{ }^{\circ} \mathrm{C}$ until extraction for RNA. Deionized water was used instead of SA solution as a control treatment. Total RNA of lily leaves was isolated using a Plant Total RNA Extraction Miniprep System (Viogene, CA, USA) and separated on $1 \%$ agarose gel prepared in $2.2 \mathrm{M}$ formaldehyde-containing $1 \times$ MOPS buffer (40 mM MOPS, pH 7.0, $10 \mathrm{mM}$ sodium acetate, $1 \mathrm{mM}$ EDTA), using $1 \times$ MOPS running buffer. The gel was transferred to a positively charged Hybond ${ }^{\mathrm{TM}}-\mathrm{N}^{+}$nylon membrane (Amersham Biosciences) by capillary transfer method. The membrane was UV cross-linked and performed hybridization with DIG-labelled target DNA probe that was prepared using PCR DIG Probe Synthesis Kit (Roche Diagnostics, Mannheim, Germany) from selected cDNA clone. Hybrids were detected with the DIG Luminescent Detection Kit for nucleic acids (Roche Diagnostics) using alkaline phosphatase-conjugated antibody against DIG (1:1000 dilution of anti-DIG-AP). The chemiluminescent signals were generated by treating membranes with $1 \%$ chemiluminescent substrate, CDPstar $^{\mathrm{TM}}$ (Tropix Inc., Bedford, MA, USA), in a buffer containing $100 \mathrm{mM}$ Tris-HCl,
$100 \mathrm{mM} \mathrm{NaCl}$, and $50 \mathrm{mM} \mathrm{MgCl}_{2}$, and recorded on Hyperfilm ${ }^{\mathrm{TM}}$ ECL film (Amersham Biosciences). In addition, B. elliptica-inoculated leaves of lily plants with or without SA treatment were examined for the amount of target mRNA transcript by the same procedure.

\subsection{Rapid amplified cDNA end (RACE)}

Total RNA and mRNA from the leaves of SA-treated lily plants were prepared by the procedures described previously for subtractive hybridization. RACE was performed to obtain $5^{\prime}$ region of the cDNA corresponding to the SA-induced mRNA using the Marathon ${ }^{\mathrm{TM}}$ cDNA Amplification Kit and Advantage 2 PCR Kit (Clontech) with the gene-specific primer and the linker-specific primer AP1, 5'-CCATCCTAATACGACTCACTATAAGGGC-3' ${ }^{\prime}$. PCR was performed with melting at $95{ }^{\circ} \mathrm{C}$ for $90 \mathrm{~s}$, five cycles of $95{ }^{\circ} \mathrm{C}$ for $1 \mathrm{~min}, 72{ }^{\circ} \mathrm{C}$ for $4 \mathrm{~min}$, five cycles of $95{ }^{\circ} \mathrm{C}$ for $1 \mathrm{~min}, 70{ }^{\circ} \mathrm{C}$ for $4 \mathrm{~min}$, and 25 cycles of $95{ }^{\circ} \mathrm{C}$ for $50 \mathrm{~s}, 68^{\circ} \mathrm{C}$ for $4 \mathrm{~min}$. The PCR product was ligated into pGEMTeasy and the resulting plasmids were transformed into E. coli $\mathrm{DH} 5 \alpha$.

\subsection{DNA sequencing and sequence analysis}

The cDNA inserts were sequenced in full by using BigDye terminator cycle sequencing ready reaction and ABI310 DNA sequencer (Perkin-Elmer, Norwalk, CT, USA). Sequence data were analyzed for similarities to known nucleotide sequences and protein sequences using the Blast program and FASTA program in Genetic Computer Group (GCG) package. The Kyte \& Doolittle hydropathy profile was generated by GREASE program in Biology WorkBench version 3.2 (http:workbench.sdsc.edu). Multiple sequence alignment was generated by ClustalW-multiple sequence alignment program in Biology WorkBench and the pairwise comparison was conducted using BESTFIT program in GCG package. In addition, the deduced amino acid sequence was analyzed by SPSCAN program at SeqWeb, and PROSITE (motif search) and Compute $\mathrm{pI} / \mathrm{Mw}$ programs (theoretical $\mathrm{pI} / \mathrm{Mw}$ ) at the ExPASy (Expert Protein Analysis System) proteomics server of the Swiss Institute of Bioinformatics.

\section{Results}

\subsection{Disease resistance of lily induced by SA}

By SA treatment in the rhizosphere, the lesion development caused by B. elliptica on the leaves of lily cv. Star Gazer was inhibited. The number of lesions appeared lower than $50 \%$ of that on the control leaves when conidial suspension was inoculated one day after SA treatment. The level of inhibition on lesion development was increased when SA solution was applied three times a week at intervals of 3 days before fungal inoculation (Fig. 1). When conidial suspension was inoculated 7 or 8 days after single treatment 


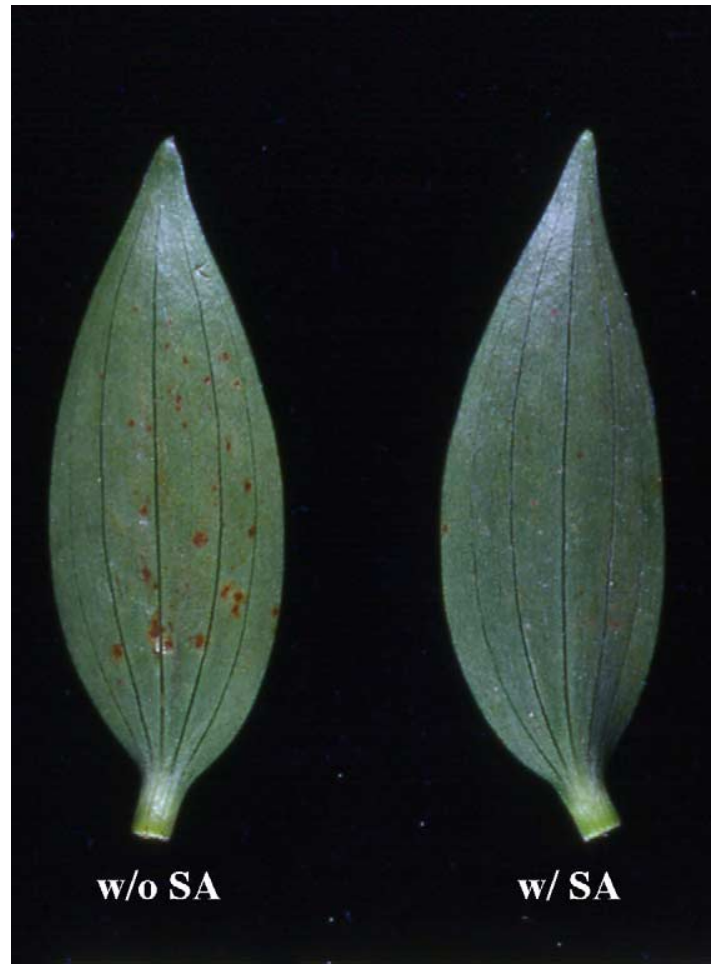

Fig. 1. The B. elliptica-inoculated leaves of lily plants pretreated with salicylic acid solution. w/SA, SA solution applied to the rhizosphere of lily plants three times a week at intervals of 3 days; w/o SA, control. The leaves were photographed 3 days after fungal inoculation.

of SA solution, the number of lesions increased to $70-80 \%$ of that on the control leaves. The suppression effect on lesion development appeared null 15 days after single treatment of SA solution, at that time the number of lesions was equivalent to that on the control leaves.

\subsection{Accumulation of $\beta-1,3$-glucan polymer and the stomatal closure of lily leaf epidermis in response to SA} treatment

The detached leaves of lily cv. Star Gazer were stained with aniline blue dye and examined by epifluorescence microscopy after different sets of treatments. Aniline blue staining demonstrated that $\beta$-1,3-glucan polymer might present in the guard cells and anticlinal walls of the epidermis of 'Star Gazer' leaves in response to SA treatment and $B$. elliptica-inoculation. The guard cells of the leaves $18 \mathrm{~h}$ after inoculation of $B$. elliptica did not appear fluorescent as that of mock inoculation when the petioles were placed in deionized water (Fig. 2(A) and (B)). Fluorescence caused by aniline blue staining also did not appear in the guard cells of the leaves treated with SA solution $18 \mathrm{~h}$ after mock inoculation (Fig. 2(C)). However, fluorescence appeared in many guard cells of SA-treated leaves $18 \mathrm{~h}$ after inoculation with B. elliptica (Fig. 2(D)). After longer incubation, fluorescence could be observed in many guard cells $72 \mathrm{~h}$ after mock inoculation on SA-treated leaves (Fig. 2(E)). However, the fluorescence could not be observed in the guard cells of B. elliptica-inoculated leaves within $72 \mathrm{~h}$ incubation period after fungal inoculation when the petioles were placed in deionized water instead of SA solution. Fluorescence also appeared in the anticlinal walls of epidermis adjacent to the guard cells of the leaves with SA treatment and mock inoculation, and the leaves treated with SA and inoculated with B. elliptica. This fluorescence was more prominent after fungal inoculation on SA-treated leaves and could be observed as early as $18 \mathrm{~h}$ after fungal inoculation (Fig. 2(F)). However, fluorescent depositions were not detected in the anticlinal walls of epidermis of the leaves infected by B. elliptica without SA treatment in our observation. On the other hand, a large portion of stomatal aperture of the epidermis of SA-treated leaves decreased to a full closure after mock inoculation in contrast to the control leaves and maintained closed after fungal inoculation. In the leaves infected by B. elliptica, without SA treatment, most of the stomata remained opened. The ratios of closed stomata were recorded and presented in Fig. 3.

\subsection{Identification of a SA-induced cDNA}

By differential screening, several cDNAs with distinct signals were detected by cDNA probes from SA-treated lily leaves. Among them, 24 cDNAs shared high homology in the nucleotide sequence as indicated by cross-hybridization. Sequence analysis revealed a 354-bp cDNA fragment coding for a truncated protein, as predicted by a putative polyadenylation signal in the $3^{\prime}$ un-translated region. This putative polypeptide shared similarity to several plant glycine-rich proteins. Northern blot analysis of leaf mRNA from SA-treated plants of lily cv. Star Gazer showed that the amount of transcript detected by this cDNA probe increased 3 days after SA treatment and slightly dropped 7 days after SA treatment. When SA was treated for seven times (once per day), the amount of RNA transcript was maintained at equivalent level as that expressed in the leaves 7 days after SA treatment (Fig. 4(A)). Therefore, the 354-bp cDNA fragment from 'Star Gazer' leaves was designated LSI (lily SA-induced).

\subsection{The transcript corresponding to LS1 in lily leaves post-fungal inoculation}

The expressions of $L S 1$-related gene in B. ellipticainoculated and upper un-inoculated 'Star Gazer' leaves were examined by northern blot analysis. The amount of $L S 1$ related transcript distinctly increased in B. elliptica-infected leaves $72 \mathrm{~h}$ after inoculation. The amount of corresponding transcript became hardly detected 6 days after inoculation in our examination. In the upper un-inoculated leaves, the amount of corresponding transcript also increased $72 \mathrm{~h}$ after inoculation on the middle leaves (Fig. 4(B)). When the lily plants were treated with SA solution, the amount of $L S 1$ related transcript increased at an earlier time after inoculation with $B$. elliptica as compared to that appeared 

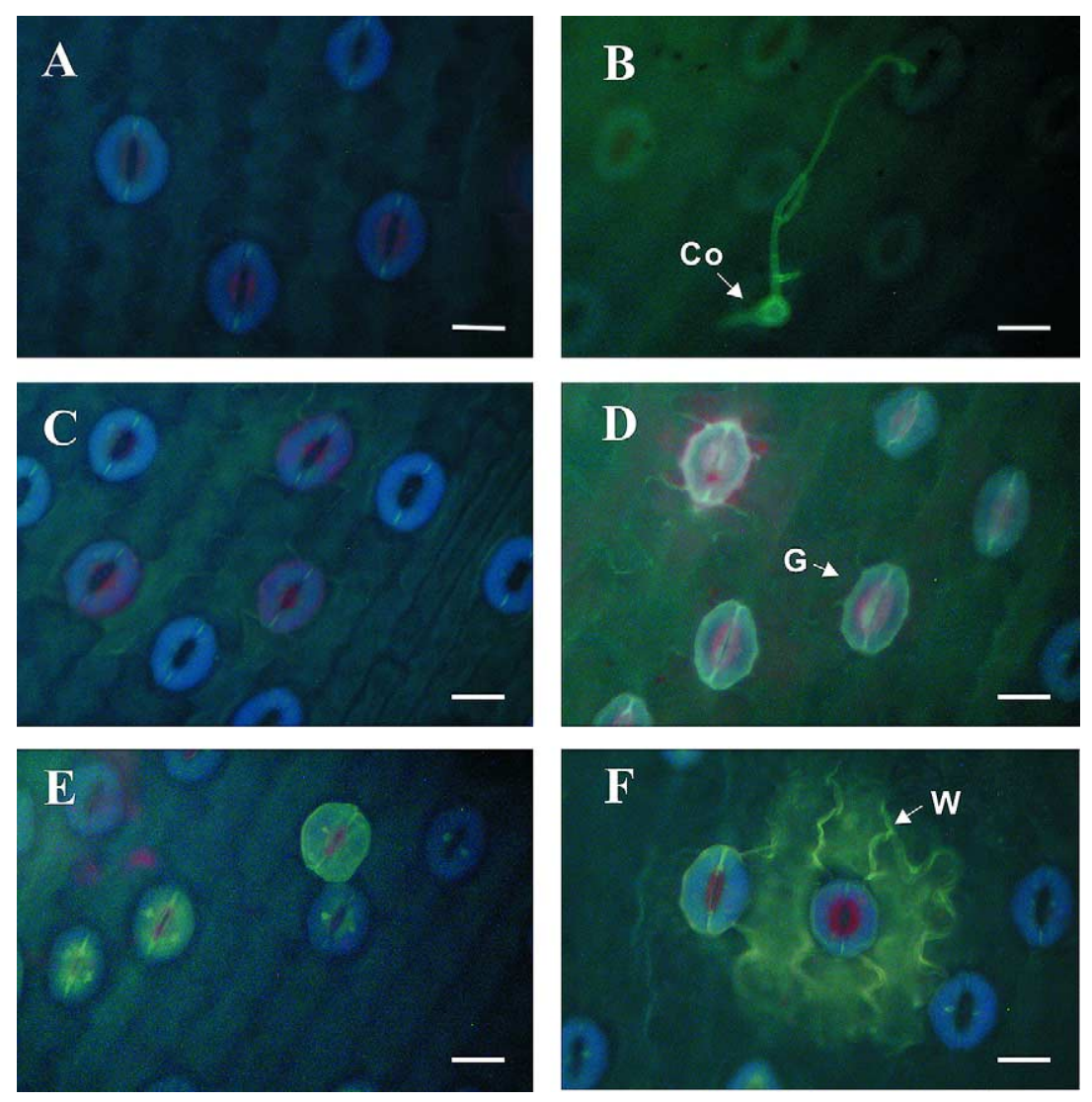

Fig. 2. Examination of lily leaves after SA treatment and/or inoculation with B. elliptica. The petioles of lily leaves immersed in deionied water or SA solution $(0.1 \mathrm{mM})$ did not show fluorescence in the guard cells $18 \mathrm{~h}$ after mock inoculation (A and C), so did the petioles of the leaves immersed in deionied water $18 \mathrm{~h}$ after inoculation with B. elliptica (B). However, fluorescence indicated by aniline blue staining appeared in the guard cells of SA-treated leaves $18 \mathrm{~h}$ after inoculation with B. elliptica (D). The fluorescence in the guard cells was observed on the leaves with SA treatment $72 \mathrm{~h}$ after mock inoculation (E). Fluorescent deposits appeared in the anticlinal walls adjacent to the guard cells of SA-treated leaves $18 \mathrm{~h}$ after inoculation with B. elliptica $(\mathrm{F})$. Lily leaves after clearing and staining process were examined by epifluorescence microscopy. Co, germinated conidium; G, guard cell; W, anticlinal walls. Bar $=50 \mu \mathrm{m}$.

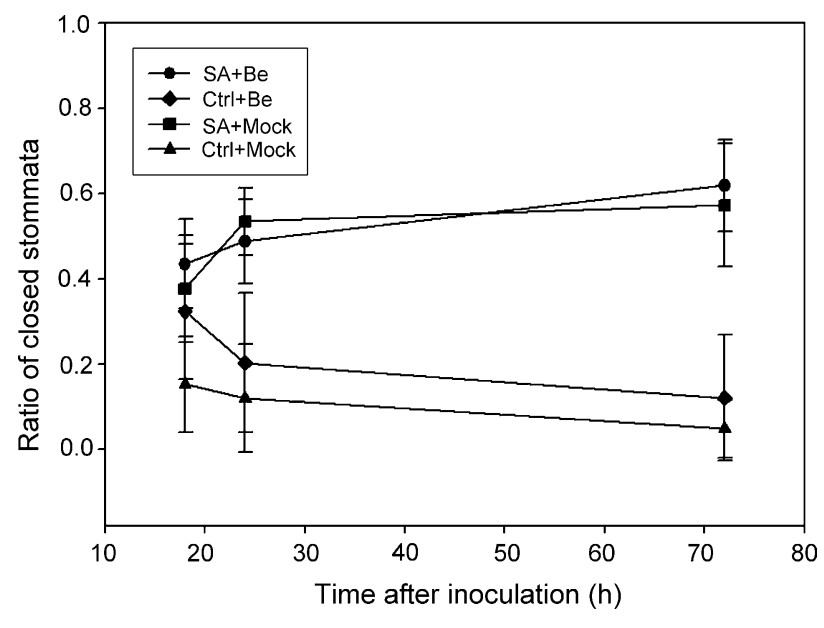

Fig. 3. Effect of SA treatment on stomatal opening of lily leaves. The ratios of closed stomata were presented based on the data from ten fields for each treatment. Deionied water was used instead of $0.1 \mathrm{mM} \mathrm{SA}$ solution as a control. Conidial suspension of B. elliptica (Be) was atomized on the abaxial surface of lily leaves one day after petiole immersed in SA solution. Tween 20 solution was used for mock inoculation. in B. elliptica-infected leaves without SA treatment. At the time of 12,24 and $48 \mathrm{~h}$ after fungal inoculation, the LSIrelated transcript distinctly increased on SA-treated leaves, but appeared low in the leaves without SA treatment. Moreover, the amounts of corresponding transcript were higher than that in the leaves with SA treatment only, at least compared to that appeared 48 and $72 \mathrm{~h}$ after SA treatment (Fig. 5).

\subsection{Coding region of a cDNA corresponding to LSI}

The LS1-specific primer LSR1, 5'-ACCGTTGTAGCAGCGTCCGCCGCCACCACC- $3^{\prime}$, was used to generate $5^{\prime}$ part of the cDNA related to $L S 1$ by $5^{\prime}$-RACE strategy. A cDNA of 365 bp including $5^{\prime}$ un-translated and $5^{\prime}$ coding regions corresponding to $L S 1$ was obtained by touchdown PCR. The compiled cDNA sequence of $664 \mathrm{bp}$ encoded a 138 amino acid protein with a predicted molecular weight of 13,760.98. The deduced protein includes an N-terminal region rich in hydrophobic and non-polar amino acids with a predicted cleavage site of signal peptidase between alanine (Ala-23) and glycine (Gly-24). The mature protein has a 
(A)

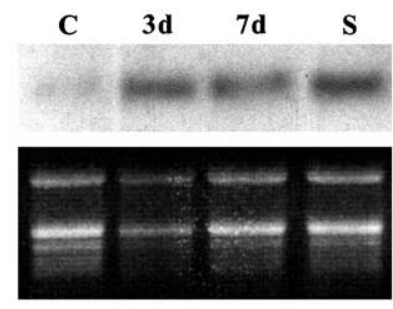

Inoculated leaves
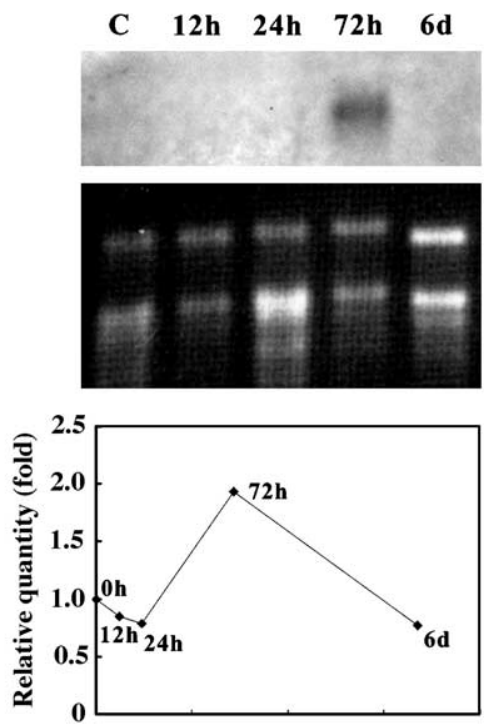

Time after inoculation

(B)

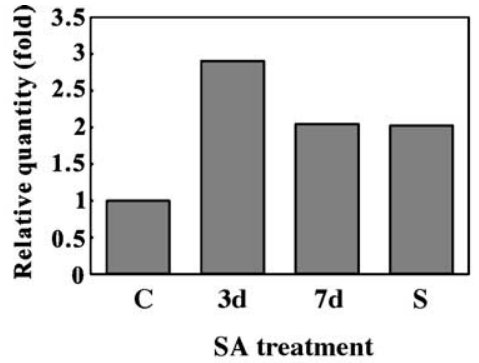

Upper, un-inoculated leaves
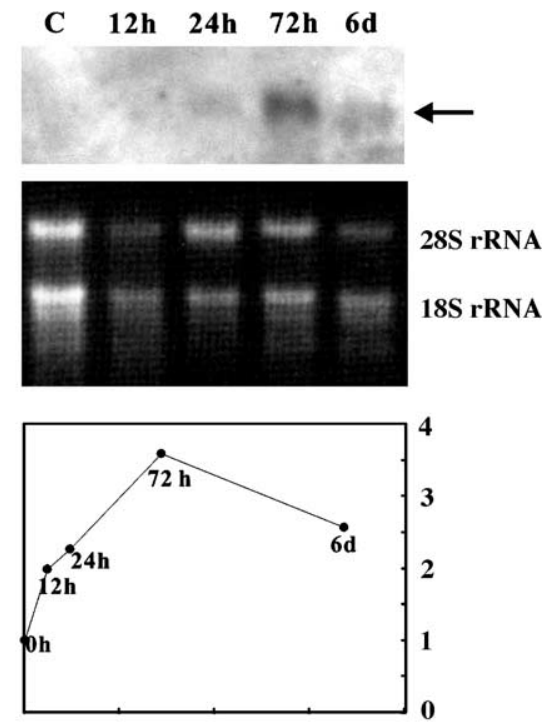
Fig. 4. Northern blot analysis of lily leaves in response to SA or B. elliptica. Total RNA was extracted from the lily leaves 3 days (3d), 7 days (7d) after SA
treatment, or with seven time-SA treatment (once per day) (S) (A, left panel). Total RNA was extracted from inoculated and upper, un-inoculated leaves 12,24 , $72 \mathrm{~h}$, or 6 days (6d) after fungal inoculation (B). C, Total RNA from control lily leaves. The signals on the blotted membrane detected by DIG-labeled LS1 probe is indicated by an arrow. The 18S rRNA and 28S rRNA are the references for the amount of total RNA loaded. The gel was exposed to UV illumination and the image was captured and analyzed by gel documentation system (Quantity-One software, BioRad) (A, right panel; B, bottom panel).

predicated molecular weight of $11,444.09$, and isoelectric point of 6.07 , and is rich in tyrosine $(\mathrm{Y})(11.3 \%)$. A cysteinerich (six in total) carboxyl terminus and a core region composed of glycine stretches, interspersed with tyrosine, proline $(\mathrm{P})$, histidine $(\mathrm{H})$ or asparagine $(\mathrm{N})$ residues were found. The glycine stretches could be easily identified in the hydropathy profile (Fig. 6). In total, the deduced amino acid

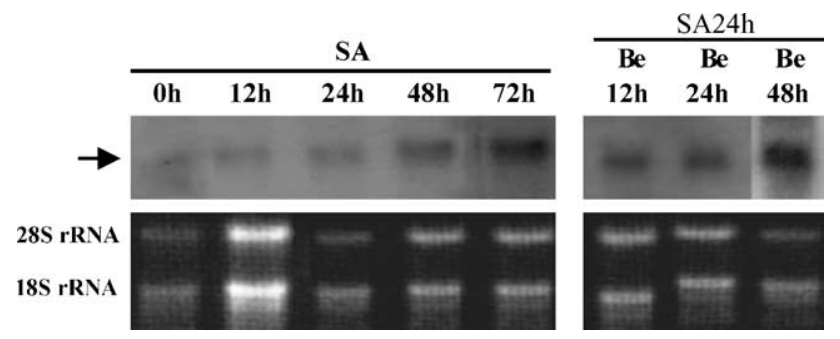

Fig. 5. Northern blot analysis of SA-treated lily leaves with or without fungal inoculation. Northern blot analysis of leaf RNA was performed different periods after SA treatment or after fungal inoculation on SAtreated lily plants. SA $24 \mathrm{~h}$, SA solution applied to the rhizosphere of lily plants $24 \mathrm{~h}$ before fungal inoculation; Be, B. elliptica. sequence contained $30.43 \%$ of glycine residues, with four repeats of YPGGGGG, two repeats of YHNGGG, and one set of YNNGGG sequence, belonging to a type of glycinerich repeat $\mathrm{GGX}_{1} \mathrm{X}_{2} \mathrm{X}_{3} \mathrm{GG}$ [24]. Therefore, this deduced protein was named LsGRP1 (Lilium cv. Star Gazer glycinerich protein 1, accession number AY072283). The putative LsGRP1 shared high similarity with various plant GRPs such as the putative GRP (BAD17439) of Oryza sativa

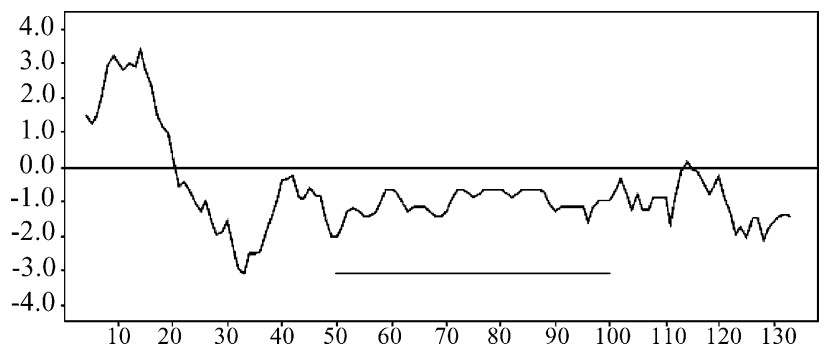

Fig. 6. Hydropathy profile of the $L S G R P 1$ cDNA. Hydropathic index of the predicted amino acid sequence is represented. The interval indicated by a bar is the glycine-rich segment. 


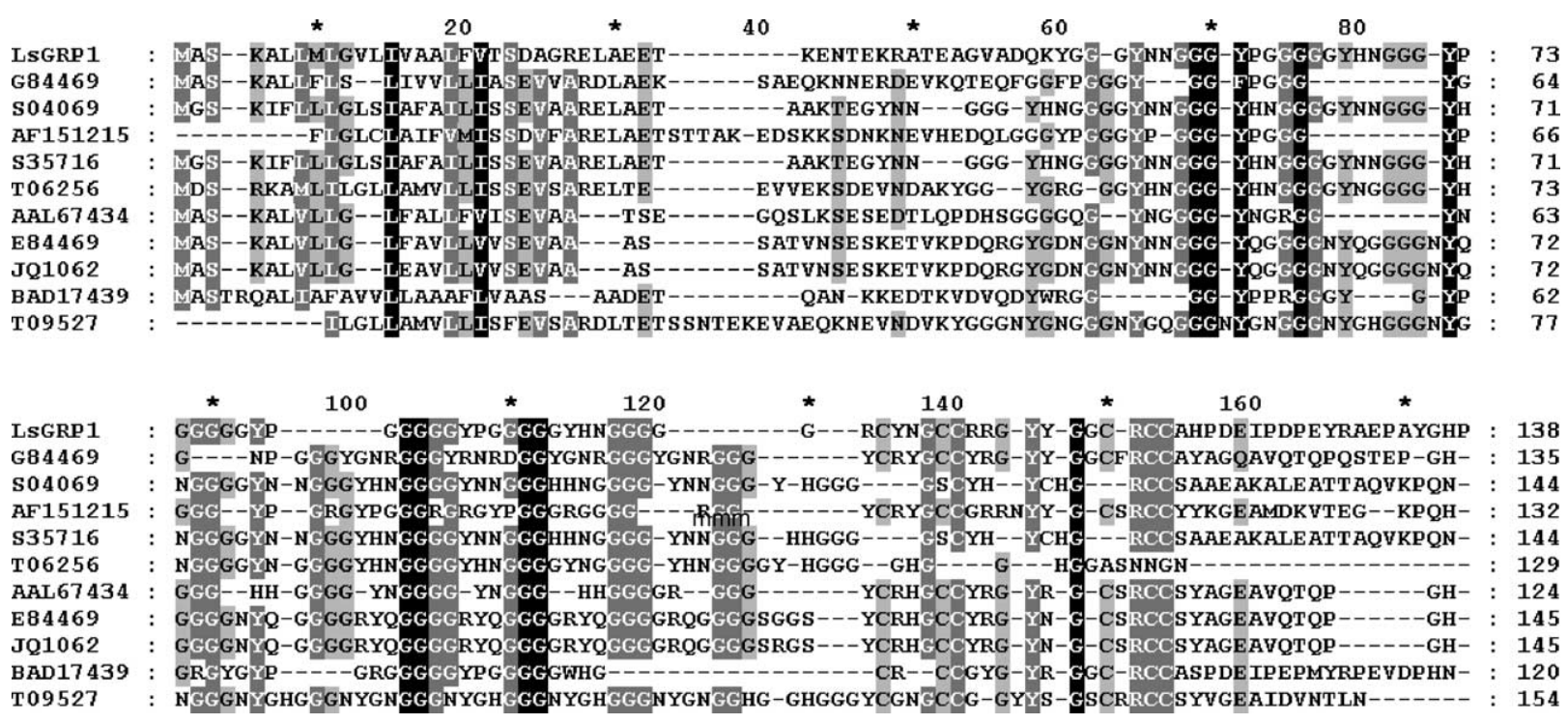

Fig. 7. Alignment of the deduced amino acid sequence of LsGRP1 with that of plant GRP homologues. The accession number corresponding to each GRP homologue is listed on the left side of the sequence. G84469, Arabidopsis probable glycine-rich protein; S04069, C. rubrum CrCH1; AF151215, N. glauca GRP1; S35716, D. carota glycine-rich protein; T06256, P. sativum PsDRM2; AAL67434, Brassica oleracea GRP1; E84469, Arabidopsis probable glycine-rich protein; JQ1062, Arabidopsis thaliana AtGRP-3 precursor; BAD17439, Oryza sativa putative glycine-rich protein; T09527, C. arietinum GRP1. Identical amino acid residues are shadowed in black and similar amino acid residues are shadowed in gray ( $80 \%$ conserved) or light gray (60\% conserved).

(68.468\%), GRP1 (AAL67434) of Brassica oleracea (63.40\%), AtGRP-3 (G84469, E84469, JQ1062) of Arabidopsis thaliana (62.21-56.06\%), CrGRP (S04069) of Chenopodium rubrum (59.69\%), GRP1 (AF151215) of Nicotiana glauca (58.197\%), glycine-rich protein (S35716) of Daucus carota (56.49\%), GRP1 (T09527) of Cicer arietinum (53.85\%), and PsDRM2 (T06256) of Pisum sativum (53.23\%). The multiple sequence alignment indicated that LsGRP1 and other GRP homologues shared conserved glycine and tyrosine residues in the glycine-rich domain (Fig. 7). A RT-PCR product of $417 \mathrm{bp}$ was obtained from the leaf mRNA of SA-treated plants of lily cv. Star Gazer by using a pair of specific primers, LSF1 (5'ATGGCTTCTAAGGCTCTTCTCATG-3') and LSR2 (5'-

Table 1

Induction of systemic resistance of lily cv. Star Gazer by B. elliptica

\begin{tabular}{lll}
\hline Days after primary inoculation $^{\mathrm{a}}$ & \multicolumn{2}{l}{$\begin{array}{l}\text { Number of lesions per leaf } \\
\text { (challenge inoculation) }\end{array}$} \\
\cline { 2 - 3 } & Experiment I & Experiment II \\
\hline $3 \mathrm{~d}$ & $34.75 \pm 5.85^{\mathrm{c}, \mathrm{d}}$ & $\mathrm{ND}$ \\
$4 \mathrm{~d}$ & $\mathrm{ND}$ & $50.59 \pm 10.55^{\mathrm{d}}$ \\
$5 \mathrm{~d}$ & $31.13 \pm 6.44^{\mathrm{d}}$ & $\mathrm{ND}$ \\
$7 \mathrm{~d}$ & $\mathrm{ND}$ & $48.10 \pm 10.82^{\mathrm{d}}$ \\
Control $^{\mathrm{b}}$ & $81.25 \pm 13.53$ & $85.37 \pm 13.40$ \\
\hline
\end{tabular}

ND: not determined.

a B. elliptica was inoculated on upper leaves different days after primary inoculation with same fungus on the middle leaves.

b Tween 20 solution was used instead of conidial suspension as a control.

${ }^{\mathrm{c}}$ Value $=$ means \pm standard deviation (five replications).

${ }^{\mathrm{d}}$ Value is significantly different at the $95 \%$ confidence level as compared to that of the control.
CTATGGGTGTCCATAAGCAGGCTC-3'), and its DNA sequence was identified equivalent to that of $L s G R P 1$.

\subsection{Systemic acquired resistance in lily cv. Star Gazer}

The upper leaves of the lily plants showed increased resistance to $B$. elliptica after primary infection by $B$. elliptica in the middle leaves. The number of lesions developed on the upper, challenged leaves appeared less when conidial suspension of $B$. elliptica was atomized 3 days after primary inoculation. In addition, this SAR phenomenon could be still observed 4, 5, and 7 days after primary inoculation (Table 1).

\section{Discussion}

SA is able to systemically protect many plants from pathogen attack, including fungal, bacterial and viral infections $[11,12,25]$. Similar to SA-mediated resistance to $B$. cinerea in tobacco [25], SA could induce systemic protection against $B$. elliptica in lily cv. Star Gazer, and that is one of the few cases of SA-induced disease resistance demonstrated in monocots $[17,26]$. Microscopical examination and molecular analysis implicated that 'Star Gazer' leaves expressed defense potential by accumulating $\beta-1,3-$ glucan polymer in the guard cells and anticlinal wall of epidermis, stimulating stomatal closure and increasing the expression of defense-related genes.

Synthesis of high molecular weight $\beta$-1,3-glucan (callose) is a prominent physical defense during fungal 
infections $[27,28]$. Callose deposited in papillae beneath fungal infection site could be observed during $B$. elliptica infection on 'Star Gazer' leaves [20]. In this study we particularly reported $\beta$-1,3-glucan might deposit in the guard cells and anticlinal walls of epidermis in response to SA treatment and inoculation with B. elliptica. Since fluorescence as shown by aniline blue staining appeared prominent in the earlier stage after fungal inoculation on SAtreated 'Star Gazer' leaves, as compared to that appeared on the leaves treated with SA or infected by B. elliptica, we presumed that SA-induced priming for potentiated defense responses against $B$. elliptica infection occurs in lily cv. Star Gazer, that is associated with an enhanced capacity for the rapid and effective activation of cellular responses after contact with challenging pathogens [29,30]. A putative callose synthase gene of Arabidopsis has been identified, whose expression is induced by SA [31]. Whether the homologue of this callose synthase gene is present in Lilium remains unclear.

The stomata and the epidermis near guard cells have been found to be the main penetration sites for B. elliptica [21]. Stomatal opening provides access to inner leaf tissues for many plant pathogens, so narrowing stomatal apertures may be advantageous for plant defense. Therefore, we predicted that stomatal closure of lily leaf epidermis induced by SA treatment would play a role in restriction of the penetration by $B$. elliptica. It has been reported that application of SA stimulates stomatal closure in many plants [32-35]. Under microscopy, the observed conidia were much less on SAtreated 'Star Gazer' leaves than that present on the leaves without SA treatment, indicating a less frequency of fungal penetration in SA-treated 'Star Gazer' leaves. Failure in penetration would cause germinated conidia easily detached from the epidermis during the clearing and staining procedure.

The defense-related genes have rarely been reported in lilies except that PR-10 transcripts were found to accumulate in the anther of Lilium longiflorum [36,37]. As known, the expression of lily PR-10 could be induced by plant hormones, abscisic acid and methyl jasmonate. However, the expression of lily PR-10 in response to SA treatment and pathogen attack has not yet been addressed. That SA successfully protected lily cv. Star Gazer from infection by B. elliptica and caused alterations of guard cells, anticlinal walls of epidermis, and the stomatal aperture stimulated us to investigate the gene expression of 'Star Gazer' leaves in response to SA treatment. A cDNA related to $L S G R P 1$ detected an increased level of corresponding transcript in the leaves of SA-treated lily plants, implicating that the expression of LsGRPI or its homologues might be regulated by SA or via SA-directed signal transduction pathway. To our knowledge, this is the first report regarding SA-induced gene expression in lilies. The gene expression of a LsGRP1 homologue, AtGRP-3 of A. thaliana, also exhibits SA-inducibility [38].

Plant GRPs represent a diverse set of proteins which may interact with RNA in the nuclei, or to be associated with cell walls or membranes [24]. The putative LsGRP1 protein with signal peptide sequence might present in extracellular matrix in its mature form, playing a role in structural enforcement or signal transduction [24,38,39]. Since plant GRPs might be grouped into families [24], the gene expression of LsGRP1 or its homologues capable of activation by SA and fungal attack is presumed. Gene expression of LsGRP1 or its homologues might be involved in the molecular mechanism of SA-induced systemic protection against $B$. elliptica in lily cv. Star Gazer. As our observations, when 'Star Gazer' leaves were treated with SA, the corresponding transcript increased at an earlier time after inoculation with $B$. elliptica as compared to that appeared in B. elliptica-infected leaves without SA treatment.

In the leaves infected by B. elliptica, accumulation of LsGRP1-related transcript was observed; thus, LsGRP1 or its homologues might play a role in the local plant defense to B. elliptica. The accumulation of $L S G R P 1$-related transcript also appeared in the upper un-inoculated 'Star Gazer' leaves, accompanied by the exhibition of acquired resistance; thus, LsGRP1 or its homologues might be involved in the protection of upper leaves from pathogen attack after primary infection by B. elliptica in the middle leaves. Gene expression of some LsGRP1 homologues, such as GRP1 of chickpea, has also been shown to be induced by fungal attack [40]. Other putative glycine-rich cell wall proteins are known to express in response to salicylate and viral infection $[41,42]$. However, a trait of systemic induction of gene expression of GRP triggered by pathogen attack was in particular noticed in our study.

\section{Acknowledgements}

We would like to thank C.-J. Huang, J.-C. Chung and Y.-H. Liu for excellent technical assistance. This work was supported by the Council of Agriculture, Taiwan, Republic of China.

\section{References}

[1] R. Hammerschmidt, Induced disease resistance: how do induced plants stop pathogens? Physiol. Mol. Plant Pathol. 55 (1999) 77-84.

[2] J. Kuc, Concepts and direction of induced systemic resistance in plants and its application, Eur. J. Plant Pathol. 107 (2001) 7-12.

[3] J.P. Métraux, C. Nawrath, T. Genoud, Systemic acquired resistance, Euphytica 124 (2002) 237-243.

[4] J.A. Ryals, U.H. Neuenschwander, M.G. Willits, A. Molina, H.-Y. Steiner, M.D. Hunt, Systemic acquired resistance, Plant Cell 8 (1996) 1809-1819.

[5] L. Sticher, B. Mauch-Mani, J.P. Métraux, Systemic acquired resistance, Annu. Rev. Phytopathol. 35 (1997) 235-270.

[6] L.C. van Loon, Induced resistance in plants and the role of pathogenesis-related proteins, Eur. J. Plant Pathol. 103 (1997) 753-765.

[7] E.A. Achuo, K. Audenaert, H. Meziane, M. Höfte, The salicylic aciddependent defence pathway is effective against different pathogens in tomato and tobacco, Plant Pathol. 53 (2004) 63-72. 
[8] J. Durner, J. Shah, D.F. Klessig, Salicylic acid and disease resistance in plants, Trends Plant Sci. 2 (1997) 266-274.

[9] B. Mauch-Mani, J.P. Métraux, Salicylic acid and systemic acquired resistance to pathogen attack, Ann. Bot. 82 (1998) 535-540.

[10] J.P. Métraux, Systemic acquired resistance and salicylic acid: current state of knowledge, Eur. J. Plant Pathol. 107 (2001) 13-18.

[11] H. Kessmann, T. Staub, C. Hofmann, T. Maetzke, J. Herzog, E. Ward, S. Uknes, J. Ryals, Induction of systemic acquired disease resistance in plants by chemicals, Annu. Rev. Phytopathol. 32 (1994) 439-459.

[12] M. Oostendorp, W. Kunz, B. Dietrich, T. Staub, Induced disease resistance in plants by chemicals, Eur. J. Plant Pathol. 107 (2001) $19-28$.

[13] T.F. Hsieh, J.W. Huang, Factors affecting disease development of Botrytis leaf blight of lily caused by Botrytis elliptica, Plant Prot. Bull. 40 (1998) 227-240.

[14] R.P. Doss, J.K. Chrisitian, G.A. Chastagner, Infection of Easter lily leaves from conidia of Botrytis elliptica, Can. J. Bot. 66 (1988) 12041208.

[15] Q. Migheli, C. Aloi, M.L. Gullino, Resistance of Botrytis elliptica to fungicides, Acta Hort. 266 (1990) 429-436.

[16] M.L. Gullino, P. Leroux, C.M. Smith, Uses and challenges of novel compounds for plant disease control, Crop Prot. 19 (2000) 1-11.

[17] C.Y. Chen, Y.Y. Lu, J.C. Chung, Induced host resistance against Botrytis leaf blight, in: H.C. Huang, S.N. Acharya (Eds.), Advances in Plant Disease Management, Research Signpost, Kerala, India, 2003, pp. 259-267.

[18] L. Diatchenko, Y.F.C. Lau, A.P. Campbell, A. Chenchik, F. Moqadam, B. Huang, S. Lukyanov, K. Lukyanov, N. Gurskaya, E.D. Sverdlov, P.D. Siebert, Suppression subtractive hybridization: a method for generating differentially regulated or tissue-specific cDNA probes and libraries, Proc. Natl. Acad. Sci. USA 93 (1996) 6025-6030.

[19] R.P. Doss, G.A. Chastagner, K.L. Riley, Techniques for inoculum production and inoculation of lily leaves with Botrytis elliptica, Plant Dis. 68 (1984) 854-856.

[20] P.F. Hou, C.Y. Chen, Early stages of infection of lily leaves by Botrytis elliptica and B. cinerea, Plant Pathol. Bull. 12 (2003) 103-108.

[21] T.F. Hsieh, J.W. Huang, T. Hsiang, Light and scanning electron microscopy studies on the infection of oriental lily leaves by Botrytis elliptica, Eur. J. Plant Pathol. 107 (2001) 571-581.

[22] W. Eschrich, H.B. Currier, Identification of callose by its diachrome and fluorochrome reactions, Stain Technol. 39 (1964) 303-307.

[23] M.E. Hood, H.D. Shew, Applications of $\mathrm{KOH}$-aniline blue fluorescence in the study of plant-fungal interactions, Phytopathology 86 (1996) 704-708.

[24] G. Sachetto-Martins, L.O. Franco, D.E. de Oliveira, Plant glycine-rich proteins: a family or just proteins with a common motif? Biochim. Biophys. Acta 1492 (2000) 1-14.

[25] A.M. Murphy, L.J. Holcombe, J.P. Carr, Characteristics of salicylic acid-induced delay in disease caused by a necrotrophic fungal pathogen in tobacco, Physiol. Mol. Plant Pathol. 57 (2000) 47-54.

[26] D.R. Walters, A.F. Mitchell, J. Hampson, A. McPherson, The induction of systemic resistance in barley to powdery mildew infection using salicylates and various phenolic acids, Ann. Appl. Biol. 122 (1993) 451-456.

[27] J.R. Aist, Papillae and related wound plugs of plant cells, Annu. Rev. Phytopathol. 14 (1976) 145-163.

[28] N.M. Donofrio, T.P. Delaney, Abnormal callose response phenotype and hypersusceptibility to Peronospora parasitica in defense-compromised Arabidopsis nim 1-1 and salicylate hydroxylase-expressing plants, Mol. Plant Microbe Interact. 14 (2001) 439-450.

[29] U. Conrath, C.M.J. Pieterse, B. Mauch-Mani, Priming in plantpathogen interactions, Trends Plant Sci. 7 (2002) 210-216.

[30] U. Conrath, O. Thulke, V. Katz, S. Schwindling, A. Kohler, Priming as a mechanism in induced systemic resistance of plants, Eur. J. Plant Pathol. 107 (2001) 113-119.

[31] L. Østergaard, M. Petersen, O. Mattsson, J. Mundy, An Arabidopsis callose synthase, Plant Mol. Biol. 49 (2002) 559-566.

[32] L. Chaerle, W. van Caeneghem, E. Messens, H. Lambers, M. van Montagu, D. van der Straeten, Presymptomatic visualization of plantvirus interactions by thermography, Nat. Biotechnol. 17 (1999) 813816.

[33] J.S. Lee, The mechanism of stomatal closing by salicylic acid in Commelina communis L., J. Plant Biol. 41 (1998) 97-102.

[34] I.C. Mori, R. Pinontoan, T. Kawano, S. Muto, Involvement of superoxide generation in salicylic acid-induced stomatal closure in Vicia faba, Plant Cell Physiol. 42 (2001) 1383-1388.

[35] S. Pennazio, D. Colariccio, P. Roggero, R. Lenzi, Effect of salicylate stress on the hypersensitive reaction of asparagus bean to tobacco necrosis virus, Physiol. Mol. Plant Pathol. 30 (1987) 347-357.

[36] J.C. Huang, F.C. Chang, C.S. Wang, Characterization of a lily tapetal transcript that shares sequence similarity with a class of intracellular pathogenesis-related (IPR) proteins, Plant Mol. Biol. 34 (1997) 681686.

[37] C.S. Wang, J.C. Huang, J.H. Hu, Characterization of two subclasses of PR-10 transcripts in lily anthers and induction of their genes through separate signal transduction pathways, Plant Mol. Biol. 40 (1999) 807-814.

[38] A.R. Park, S.K. Cho, U.J. Yun, M.Y. Jin, S.H. Lee, G. SachettoMartins, O.K. Park, Interaction of the Arabidopsis receptor protein kinase Wak1 with a glycine-rich protein, AtGRP-3, J. Biol. Chem. 276 (2001) 26688-26693.

[39] C. Ringli, B. Keller, U. Ryser, Glycine-rich proteins as structural components of plant cell walls, Cell. Mol. Life Sci. 58 (2001) 14301441.

[40] H. Cornels, Y. Ichinose, W. Barz, Characterization of cDNAs encoding two glycine-rich proteins in chickpea (Cicer arietinum L.): accumulation in response to fungal infection and other stress factors, Plant Sci. 154 (2000) 83-88.

[41] H.J.M. Linthorst, L.C. van Loon, J. Memelink, J.F. Bol, Characterization of cDNA clones for a virus-inducible, glycine-rich protein from petunia, Plant Mol. Biol. 15 (1990) 521-523.

[42] M.D. van de Rhee, J.A.L. van Kan, M.T. González-Jaén, J.F. Bol, Analysis of regulatory elements involved in the induction of two tobacco genes by salicylate treatment and virus infection, Plant Cell 2 (1990) 357-366. 